\title{
EFEITO DE UM PROGRAMA DE EXERCÍCIOS FÍ́SICOS NA FORÇA DE PREENSÃO PALMAR EM IDOSOS INSTITUCIONALIZADOS
}

Jonathas da Silva Moraes/ Bacharel em Educação Física ULBRA Canoas/ jonathasmoraes@yahoo.com.br

Lidiane Requia Alli-Feldmann/ Doutora pela UFCSPA, docente da Universidade Luterana do Brasil/ lidianefeldmann@gmail.com

Kelly Diana Pereira da Cruz/ Acadêmica de Educação Física ULBRA Canoas/ kellybonja@yahoo.com.br Jadiani Fucilini Martins/ Bacharel em Educação Física ULBRA Canoas/ jadi_martins@hotmail.com Lucimara de Souza Pereira/ Bacharel em Educação Física ULBRA Canoas/ lucipereira2019@gmail.com

Daniel da Rosa Vieira/ Bacharel em Educação Física ULBRA Canoas/ danieldrvieira@gmail.com Rebecca Moreira Franco/ Licenciada em Educação Física ULBRA Canoas e Acadêmica bacharel em Educação Física ULBRA/ rebeccamfranco@hotmail.com

\section{RESUMO}

Introdução:A Força de Preensão Palmar(FPP) é um importante medidor de força para membros superiores; com ele pode-se mensurar a condição de saúde, grau de independência e funcionalidade do indivíduo. Objetivo: Verificar os efeitos na força de preensão palmar em idosos residentes de uma Instituição de Longa Permanência para Idosos (ILPI), antes e após um programa de exercícios físicos aplicados durante 6 meses. Método: A amostra foi composta por 15 idosos com média de 77,2 anos \pm 7,5, sendo 9 mulheres e 06 homens, residentes de ILPI. Nos critérios de exclusão os indivíduos não poderiam apresentar limitação física que impedisse a prática de atividades físicas, foi utilizado um dinamômetro digital, a preensão palmar foi registrada em quilograma-força (kgf), ajustou-se para cada indivíduo de acordo com o tamanho das mãos, realizando três medidas para a mão esquerda e três para a direita, com um período recuperatório de um minuto entre as tentativas, no final a média das três medidas era o valor da FPP. Resultados: Os resultados mostram que não foi encontrado valores significativos estatisticamente na FPP, no entanto, ao observarmos as médias de antes e depois nota-se um aumento tanto da mão esquerda quanto da direita após o período em que foi introduzido o programa de exercícios físicos; a FPP direita teve um acréscimo de 0,7066 kgf equivalente a um aumento de 4,47\%, já a FPP esquerda obteve 1,9786 kgf equivalente a um aumento de 13,04\%.Conclusão:Sugere-se que um programa de exercícios físicos nas ILPIs,influencia positivamente na sociabilidade, disposição e autonomia.

Palavras-chave: Força de Preensão Palmar, Idosos, Força Membros Superiores 